REVISTA DE DERECHO UNED, NÚM. 19, 2016

\title{
EUTANASIA Y SUICIDIO ASISTIDO EN CANADÁ \\ Una panorámica de la sentencia Carter v. Canadá y del consiguiente Proyecto de Ley C-14 presentado por el Gobierno canadiense
}

EUTHANASIA UND ASSISTED SUICIDE IN CANADA

An overview of the Judgment Carter v. Canada and therefore Bill C-14 presented by the Canadian Government

José Francisco GimBel García

Doctorando en el Programa de Derecho y Ciencias Sociales (UNED)

\section{OCTUBRE 2016}

Resumen: En la sentencia Carter v. Canadá, los magistrados de la Corte Suprema de Canadá han venido a reconocer por unanimidad que la prohibición absoluta de la ayuda médica para morir (la eutanasia activa directa y el suicidio asistido por médico), aplicada a determinadas personas y en determinadas condiciones, puede violar el contenido esencial del derecho fundamental a la vida, la libertad y la seguridad personal reconocido en el artículo 7 de Carta Magna canadiense. En el presente artículo se pretende ofrecer una panorámica a propósito de la Sentencia de la Corte Suprema de Canadá, de 6 de febrero de 2015, en el asunto Carter v. Canadá, así como una descripción de la Propuesta de Ley C-14 que, como consecuencia de esta Sentencia, presentó el Gobierno canadiense en abril del año siguiente. Se pretende, en definitiva, hacerse cargo de los elementos centrales que sustentan un fallo judicial y una Ley que, de aprobarse, marcará sin duda un antes y un después en el debate a propósito de la disponibilidad de la propia vida en contextos eutanásicos. 
Abstract: In the sentence Carter v. Canada, the judges of the Supreme Court of Canada have come to recognize unanimously that the absolute prohibition of medical aid in dying (direct active euthanasia and physician-assisted suicide), applied to certain individuals and under certain conditions, may violate the essential content of the fundamental right to life, liberty and personal security recognized in the art. 7 Canadian Magna Carta. This article is intended to offer a panoramic view with regard to the judgment of the Supreme Court of Canada, on February 6, 2015, in Carter v subject. Canada, as well as a description of the proposed of law $\mathrm{C}-14$ which, as a result of this sentence, presented it to the Canadian government in April of the following year. Intends, in short, take charge of the core elements that sustain a court ruling and a law that, if approved, will mark certainly a before and an after in the debate with regard to the availability of life itself in euthanasia contexts.

Palabras clave: suicidio asistido, eutanasia, bioderecho, asunto Carter v. Canadá, derechos fundamentales

Keywords: assisted suicide, euthanasia, biolaw, Carter v. Canada, fundamental rights

Recepción original: 03/10/2016.

Aceptación original: 10/10/2016.

Sumario: I. Introducción. II. Un primer acercamiento a la sentencia. II.A. El problema social, el conflicto jurídico, y el fallo. II.B. La demanda. II.C. Historial judicial. II.C.1. Decisión en primera instancia. II.C.2. Apelación y jurisprudencia en el caso Rodríguez. III. Argumentario básico de la sentencia y conflicto de derechos. III.A. El derecho a la vida. III.A.1. Sobre su naturaleza. III.A. 2. Riesgos asociados a la legalización. III.B. El derecho de libertad. III.C. Adecuación a los principios fundamentales de justicia y juicio de proporcionalidad. III.D. El fallo. IV. Propuesta de Ley C-14 Del Gobierno Canadiense. IV.A. Modificación del Código penal en orden a crear excepciones para el delito de homicidio consentido, la ayuda en el suicidio, y la administración de sustancias nocivas. IV.B. Definiciones y sistema de garantías. IV.C. Seguimiento y control de los procesos. IV.D. Régimen sancionador. V. Conclusiones. 


\section{INTRODUCCIÓN}

Quizás no resulte del todo baladí dedicar algunas palabras introductorias a contextualizar el escenario social, económico y político, así como los términos del debate conceptual que tiene lugar en el momento que ven la luz tanto la Sentencia Carter v. Canadá como el posterior Proyecto de Ley C-14 que serán objeto de comentario.

Existe coincidencia casi universal en la afirmación de que vivimos tiempos de cambio, de transformación. En la raíz (vale decir que en la base material) de buena parte de estos cambios económicos, sociales y políticos que vivimos se encuentra un desarrollo vertiginoso de las fuerzas productivas en forma de lo que se ha venido a denominar revolución científico-técnica.

Estos cambios, muchos de ellos de naturaleza estructural (algunos autores optan por denominarlos sistémicos o civilizatorios), están poniendo en cuestión ciertas «verdades» que hasta hace no mucho parecían inmutables en el ámbito de la ética, las relaciones sociales y el derecho. Al igual que en su momento las preguntas de Galileo acerca de la posición de nuestro planeta en el universo, o las preguntas de Mendel acerca del origen y posición de los seres humanos en la naturaleza conocida, sirvieron para cuestionar aspectos tradicionales de la percepción que teníamos sobre nuestra especie, los terrenos inexplorados por los que viene desarrollándose la biología y las ciencias de salud en las tres últimas décadas, la llamada biotecnología, están igualmente poniendo en cuestión ciertos paradigmas que parecían hasta hace poco no sólo incuestionables sino incluso inaccesibles al conocimiento y la mano del hombre.

En este contexto, no es de extrañar que el poder emergente de la tecnología médica, en relación con el final de la existencia humana, este exigiendo a ojos de muchos especialistas un reajuste en la definición del sistema de derechos, incluidos los derechos fundamentales, en orden a dotar a los individuos y a la sociedad de herramientas jurídicas y políticas que les permita protegerse del vendaval tecnológico al que estamos asistiendo, en el que no todos son ventajas.

En este orden de cosas, es importante dejar constancia de que, en paralelo al desarrollo de los avances científicos y tecnológicos -y en parte como consecuencia de ellos- se está produciendo un cambio de paradigma en el ámbito sanitario que tiene que ver con la emergencia del valor de la autonomía personal de las personas, cambio este que está modificando profundamente los valores de la relación clíni- 
ca y que algunos autores asocian a la llegada del derecho a la libertad de conciencia aplicada a la gestión del propio cuerpo.

El ciudadano, el individuo, la persona en definitiva, se ha convertido -se está convirtiendo- en el eje del sistema sanitario. Ante los ojos -vale decir ante la sensibilidad y la conciencia- de cada vez mayor número de personas, se percibe con claridad que, en una sociedad democrática, el respeto a la libertad y autonomía de la voluntad de la persona -no ya del médico, no ya del entorno familiar- han de mantenerse durante la enfermedad y alcanzar plenamente al proceso de la muerte. Ahora bien, este cambio de paradigma -al menos desde el punto de vista de quien esto escribe- no está resultando un proceso ni lineal ni pacífico.

En una rápida ojeada al ámbito del derecho comparado puede constatarse la existencia de un cierto nivel de acuerdo -no unánime, pero sí muy generalizado- a propósito de tres tipos de acciones: a) la necesidad del consentimiento informado -es el paciente el que decide sobre la aplicación o interrupción de los tratamientos a los que va a ser sometido -, b) el derecho de los pacientes a combatir el dolor con analgésicos, o incluso con sedaciones en el caso de padecer síntomas refractarios, aunque eso suponga un acortamiento de la vida; y c) la limitación de medidas de soporte vital, con el fin de evitar el llamado «encarnizamiento terapéutico». No existe consenso, sin embargo, al respecto de lo que se ha dado en llamar como «ayuda médica para morir», es decir, respecto del suicidio asistido por médico o la eutanasia, conceptos estos que constituyen el núcleo básico de la Sentencia y del posterior Proyecto de Ley que son objeto de estudio en el presente artículo.

Así pues, el paisaje jurídico y legislativo internacional, en lo que a la «ayuda médica para morir» se refiere, se resumiría afirmando que tales conductas son constitutivas de delito en la mayoría de los países occidentales, excepción hecha de ocho jurisdicciones que permiten alguna forma de la muerte asistida: los Países Bajos, Bélgica, Luxemburgo, Suiza, Oregón, Washington, Montana y Columbia.

\section{UN PRIMER ACERCAMIENTO A LA SENTENCIA}

\section{II.A. El problema social, el conflicto jurídico, y el fallo}

Constata la Corte Suprema de Canadá en el parágrafo primero de la Sentencia el problema social sobre el que se pretende actuar, problema éste que tiene su base en que en Canadá, como en nuestro país, es delito ayudar a otra persona a poner fin a su propia vida 
[art. 241. b) Criminal Code]. Como consecuencia de esta penalización, las personas que están grave e irremediablemente enfermas no pueden solicitar la asistencia médica para morir estando condenadas, en palabras de la propia Corte, "...a una vida de sufrimiento grave e intolerable». Estas personas se enfrentan a la siguiente dicotomía: pueden quitarse la vida antes de tiempo, a menudo por medios violentos o peligrosos, o puede sufrir hasta que muera por causas naturales. En ambos casos, en opinión de los redactores de la Sentencia, «la elección es cruel».

De este problema social se infiere otro de naturaleza jurídica, que los magistrados formulan de la siguiente forma: la prohibición criminal que pone a la persona en esta suerte de macabra elección ¿viola la Carta Canadiense de Derechos y Libertades (en adelante CCDL), concretamente los artículos 7 (el derecho a la vida, a la libertad y a la seguridad de la persona) y 15 (igualdad de trato por y bajo la ley) de la citada Carta magna? Ciertamente, se trata de un problema en el que hay que equilibrar valores y derechos en aparente competencia que resultan de gran importancia. De un lado, se encuentra «la autonomía y la dignidad de un adulto competente que busca la muerte como respuesta a una condición médica grave e irremediable. Por otra, la santidad de la vida y la necesidad de proteger a los vulnerables» ${ }^{1}$

Pues bien, la Corte Suprema se muestra de acuerdo con la conclusión que, después de una exhaustiva revisión del caso, realizo en su día el juez de primera instancia: el artículo 241.b) del Código Penal canadiense supone una violación grave del derecho a la vida, a la libertad y a la seguridad de la persona consagrado en el art. 7 del CCDL; constata igualmente el fallo de la Sentencia otro asunto que, más adelante, se convertirá en uno de los aspectos centrales del problema: la convicción por parte de todos los magistrados de la Corte (la Sentencia se firmó por unanimidad de sus miembros) de que «... un régimen regulatorio administrado correctamente es capaz de proteger a los más vulnerables de abuso o error» ${ }^{2}$.

Pero, más allá del fallo, lo que resulta crucial en mi opinión es el argumentario general utilizado en la Sentencia por los distintos actores implicados en la misma. Comencemos analizando los argumentos contenidos en la demanda.

${ }^{1}$ Corte Suprema de Canadá. Sentencia Carter v. Canadá (Fiscal General), de 6 de febrero de 2015. Expediente 35.591, parágrafo 2.

2 Ibídem, parágrafo 3. 


\section{II.B. La demanda}

En el año 2009 Gloria Taylor fue diagnosticada con una enfermedad neurodegenerativa fatal denominada esclerosis lateral amiotrófica (ELA). Los pacientes con esta enfermedad padecen una debilidad muscular progresiva, de modo que primero pierden la capacidad de utilizar sus manos y pies, más tarde la capacidad de caminar, de tragar, de hablar y, con el tiempo, la capacidad de respirar.

Gloria Taylor presentó una demanda ante el Tribunal Supremo de la Columbia Británica solicitando una muerte con asistencia médica, con el fin de «no morir lentamente, pieza por pieza» o «atormentada por el dolor». Estas fueron las palabras que utilizó Gloria Taylor para argumentar su petición: "Yo no quiero que mi vida termine con violencia. Yo no quiero que mi modo de muerte sea traumático para los miembros de mi familia. Quiero el derecho legal a morir en paz, en el momento de mi propia elección, en el abrazo de mi familia y amigos. Yo sé que me estoy muriendo, pero estoy muy lejos de estar deprimida. Tengo algo de tiempo -que es parte integrante de la experiencia de saber que eres un enfermo terminal. Pero todavía hay muchas cosas buenas en mi vida; todavía hay cosas, como momentos especiales con mi nieta y familia, que me traen una alegría extrema. No voy a perder el tiempo que me queda en estar deprimida. Tengo la intención de conseguir toda la felicidad que pueda extraer de lo que queda de mi vida, siempre y cuando se mantenga una vida de calidad; pero yo no quiero vivir una vida sin calidad. Llegará un momento en que voy a saber que ya es suficiente. No puedo decir exactamente cuando ese tiempo será. No es una cuestión de 'cuando no puedo caminar' o 'cuando no puedo hablar'. No hay un momento preestablecido. Sólo sé que habrá algún momento en el tiempo cuando voy a ser capaz de decir: 'esto es todo, este es el punto donde la vida no vale la pena'. Cuando llegue ese momento, quiero ser capaz de llamar a mi familia unida, decirles de mi decisión, decir un adiós digno y obtener un cierre final -para mí y para ellos. Mi calidad de vida actual se ve afectada por el hecho de que no puedo decir con certeza que voy a tener el derecho de pedir el auxilio médico al morir cuando llegue el momento del 'ya basta'. Yo vivo en el temor de que mi muerte será lenta, difícil, desagradable, dolorosa, indigna e inconsistente con los valores y principios que he tratado de vivir.... ${ }^{3}$

Las leyes canadienses, empero, no permitían atender la solicitud de la señora Taylor en ninguna de las formas que pudiera concretarse

\footnotetext{
3 Ibídem, parágrafo 12.
} 
ésta, y tampoco contaba con los recursos económicos suficientes para viajar a Suiza, donde el suicidio asistido es legal y disponible para los no residentes. Como ya ha quedado dicho, este estado de cosas la dejaba ante la elección de a) matarse a sí misma mientras aún era físicamente capaz de hacerlo, o b) renunciar a la capacidad de ejercer control alguno sobre la forma y el momento de su muerte. La incapacidad de traer un final pacífico a su vida en el momento y de la manera que estimen conveniente, según las pruebas de testigos aportadas en el sumario, genera un sufrimiento psíquico en absoluto desdeñable para muchos enfermos terminales o pacientes con minusvalías graves crónicas. De hecho, constata la Sentencia objeto de estudio que «Varios de los testigos declararon que ellos o sus seres queridos habían previsto o, de hecho, se suicidaron antes de lo que hubiesen elegido si la muerte asistida por un médico hubiera estado disponible para ellos. Una mujer señaló que 'los métodos convencionales de suicidio, como la asfixia por monóxido de carbono, corte de las muñecas o de una sobredosis de drogas de la calle, requerirían que terminan su vida, mientras aún estoy sano y capaz de tomar mi vida, muy por delante de cuando realmente necesito salir de esta vida'»4.

Es importante comprender, para poder captar posteriormente en toda su amplitud la argumentación y el fallo final del Tribunal, que la solicitud de la demanda («el derecho de pedir el auxilio médico al morir cuando llegue el momento») no se refiere a la validez constitucional de la prohibición penal de la ayuda al suicidio asistido por médico, ni tampoco de la eutanasia activa directa, sino que utilizan un concepto («auxilio médico al morir») que puede comprender, al menos en opinión del Tribunal, ambas prácticas.

Los demandantes utilizan las expresiones «suicidio médicamente asistido» $\mathrm{y}$ «morir asistido por un médico» para describir la situación en la que un médico proporciona o administra la medicación que trae intencionalmente la muerte de la paciente, a petición del paciente. En ese sentido, los recurrentes realizan dos afirmaciones clave: a) que la prohibición de morir asistido por un médico priva a los adultos competentes que sufran una condición médica grave e irremediable -y que tienen que soportar como consecuencia sufrimientos físicos o psicológicos que resultan intolerables para esa persona- de su derecho a la vida, a la libertad y a la seguridad (art. 7 de la CCDL); y b) que la prohibición priva a los adultos que tienen una discapacidad física de su derecho a la igualdad (art. 15 de la CCDL).

\footnotetext{
${ }^{4}$ Ibídem, parágrafo 15.
} 


\section{II.C. Historial judicial}

\section{II.C.1. Decisión en primera instancia}

Así pues, a raíz de la demanda presentada, el juez de primera instancia tuvo que plantearse si la prohibición de ayuda para morir que constaba en el Código Penal canadiense violaba los artículos 7 y 15 de su Constitución, referida a las garantías de libertad y de igualdad. Se razonaba en primera instancia que, si bien el objetivo de la prohibición general (que el juez sitúa en la protección de las personas vulnerables que pudieran verse inducidas a cometer suicidio en un momento de debilidad) está racionalmente conectado con el fin, un sistema estrictamente limitado de excepciones cuidadosamente monitoreado también podría cumplir ese objetivo. Dicho en palabras de la propia Sentencia «El permiso para la muerte con asistencia médica para las personas gravemente enfermas y que sufren irremediablemente, que sean competentes, plenamente informados, no ambivalente, y libre de coerción o coacción, con garantías estrictas de cumplimiento» podría alcanzar ese mismo objetivo de protección de las personas vulnerables «de una manera real y sustancial $»^{5}$. Así pues, el juez de primera instancia concluyó que la prohibición era más amplia de lo necesaria, ya que la evidencia había mostrado que, en su opinión, un sistema con garantías adecuadamente diseñados y administrados ofrece un medio menos restrictivo para alcanzar el objetivo propuesto. De alguna forma, los graves efectos negativos de la prohibición absoluta aparecían desproporcionados en relación con sus efectos positivos.

\section{II.C.2. Apelación y jurisprudencia en el caso Rodríguez}

La mayoría de la Corte de Apelaciones permitió el recurso del estado canadiense a la Sentencia que se produjo en primera instancia, basándose en el argumento de que el juez estaba obligado a seguir la decisión de la Corte Suprema en el caso Rodríguez v Canadá. La Corte de Apelaciones ${ }^{6}$ concluyó que, ni los cambios producidos en el ámbito social y legislativo, ni los nuevos problemas jurídicos invocados por el juez de primera instancia, permitían una salida distinta de lo decidido en el caso Rodríguez veintiún años antes.

Los hechos en el caso Rodríguez eran muy similares a los reconocidos como tales en el caso Carter: ambas eran mujeres, ambas estaban

\footnotetext{
5 Ibídem, parágrafo 29.

${ }^{6}$ Corte Suprema A. Columbia Británica, 2012 BCSC 886, 287 CCC (3d) 1.
} 
muriendo de ELA, y ambas solicitaban la asistencia médica para morir cuando su sufrimiento se hiciera intolerable. En el caso Rodríguez, la mayoría de la Corte sostuvo que la prohibición privó a la Sra. Rodríguez de la seguridad de la persona ${ }^{7}$, e igualmente entendió que la disposición (el art. 241 del Código Penal canadiense) violaba el principio de no discriminación $^{8}$, pero encontró que se hizo de una manera que estaba de acuerdo con los principios establecidos en el artículo 1 de la CCDL ${ }^{9}$.

A pesar de la decisión de la Corte en Rodríguez, el debate social, jurídico y político sobre la muerte con asistencia médico continuó en Canadá. La propia Corte Suprema constata en su Sentencia que «Entre 1991 y 2010, la Cámara de los Comunes y sus comisiones debatieron no menos de seis proyectos de ley de miembros privados que buscaban despenalizar el suicidio asistido. Ninguno fue aprobado» ${ }^{10}$. Mientras que los opositores a la legalización hacían hincapié en la insuficiencia de las garantías y la posibilidad de devaluar la vida humana, una minoría se pronunció a favor de la reforma, destacando la importancia de la dignidad y la autonomía y los límites de los cuidados paliativos para abordar el sufrimiento. El Senado canadiense consideró el asunto con la emisión de un informe sobre el suicidio asistido y la eutanasia en 1995. La mayoría expresó su preocupación por el riesgo de abuso en un régimen permisivo y la necesidad de respeto a la vida. Una minoría apoyó una exención a la prohibición en algunas circunstancias.

Como quedó evidenciado en la apelación realizada al fallo en primera instancia, y antes de entrar al fondo del asunto, la Corte Suprema debía dilucidar la duda de si el Tribunal inferior del que procedía la causa, es decir, la Corte Suprema de la Columbia Británica, podía o no desvincularse del precedente establecido por la Corte Suprema de Canadá en el caso Rodríguez, ya que, efectivamente, la doctrina de que los tribunales inferiores deben seguir las decisiones de los tribu-

${ }^{7} \mathrm{El}$ art. 7 de la Carta Canadiense de Derechos y Libertades tiene un texto del siguiente tenor: «Todos tendrán el derecho a la vida, a la libertad y a la seguridad de su persona; y nadie podrá atentar contra este derecho, excepto cuando sea en conformidad con principios de justicia fundamental».

${ }^{8} \mathrm{El}$ art. 15 de la Carta Canadiense de Derechos y Libertades tiene un texto del siguiente tenor: «todos son iguales ante la ley y ésta se aplica igualmente a todos, y todos tienen derecho a la misma protección y al mismo beneficio de la ley, independiente de toda discriminación, especialmente de discriminación fundada en raza, origen nacional o étnico, color, religión, sexo, edad o deficiencias mentales o físicas».

${ }_{9} \mathrm{El}$ art. 1 de la Carta Canadiense de Derechos y Libertades dice: «La Carta Canadiense de Derechos y Libertades garantiza los derechos y libertades establecidos en la misma, sujetos solamente a restricciones razonables prescritas por la ley y cuya justificación pueda demostrarse en una sociedad libre y democrática».

${ }^{10}$ Ibídem, parágrafo 6. 
nales superiores es fundamental en cualquier estado de derecho que se precie, y eso también vale para el sistema canadiense. Sin embargo, y con el fin de evitar la petrificación de todo el corpus legislativo y judicial, los tribunales pueden reconsiderar resoluciones de tribunales superiores. En el caso canadiense, esta reconsideración puede producirse en dos situaciones a) cuando se presenta un nuevo problema legal y b) cuando hay un cambio de las circunstancias o pruebas que cambian radicalmente los parámetros del debate. En opinión del juez de primera instancia, y opinión también de la Corte Suprema, ambas condiciones se cumplían en el caso Carter.

Efectivamente, la matriz de datos legislativos y sociales que daban pie a la pruebas presentadas en el caso Rodríguez se basaron en a) la aceptación generalizada de una distinción moral o ética entre eutanasia activa y eutanasia pasiva, b) la falta de una «medida a mitad de camino» que pudiera proteger a los vulnerables, y c) el «consenso sustancial» en los países occidentales de que es necesaria una prohibición general para la protección contra la pendiente resbaladiza. Pues bien, en opinión de la Corte Suprema «...el registro ante el juez de primera instancia en este caso contenía pruebas que, de ser aceptadas, eran capaces de minar cada una de estas conclusiones» ${ }^{11}$.

\section{ARGUMENTARIO BÁSICO DE LA SENTENCIA Y CONFLICTO DE DERECHOS}

\section{III.A. El derecho a la vida}

\section{III.A.1. Sobre su naturaleza}

Como ha quedado dicho, la prohibición penal que impide la muerte asistida por médico tuvo el efecto de obligar a algunas personas a quitarse la vida antes de tiempo, por miedo a no ser capaces de hacerlo cuando hubieran alcanzado -en función de la evolución de su enfermedad- un sufrimiento intolerable. Este hecho, en opinión de la Corte Suprema, nunca fue cuestionado por la Fiscalía General.

Constata igualmente la Sentencia algunas opiniones judiciales relevantes ${ }^{12}$ en línea a que el derecho a la vida protege algo más que su mera existencia física. Así, el Juez Finch, es de la opinión de que el

${ }^{11}$ Ibídem, parágrafo 47.

${ }^{12}$ La del Juez Finch en su voto particular en la Corte de Apelaciones en la Sentencia del caso Carter v Canadá, y la del Juez Cory, en su voto particular a la sentencia Rodríguez. 
usufructo de la vida está «íntimamente ligado a la forma en que una persona valora su experiencia vivida. El punto en que se pierde el sentido de la vida, cuando los atributos positivos de la vida están tan disminuidos que haga que carece de valor la vida,...es una decisión muy personal que 'todo el mundo' tiene el derecho de hacer por sí mismo", de modo tal que el derecho a la vida, en la medida en que morir es una parte integral de esta, incluye el derecho a morir con dignidad.

Sobre la base de estas premisas, no entiende la Corte Suprema que la formulación existencial del derecho a la vida requiera de una prohibición absoluta de la ayuda para morir, o que los individuos no puedan renunciar a su derecho a la vida. Esto crearía, en opinión del Tribunal, un «deber de vivir», en lugar de un «derecho a la vida», y pondría en tela de juicio, por ejemplo, la retirada o denegación de tratamientos de soporte vital o la utilización de la sedación paliativa aunque esta acorte la vida del paciente. Reconoce igualmente la Sentencia ${ }^{13}$ que la santidad de la vida es uno de nuestros valores sociales más importantes, si bien ese concepto de santidad ya no consiste en exigir que toda vida humana sea preservada a toda costa.

Es decir, el Tribunal niega que pueda otorgarse un valor absoluto al derecho a la vida reconocido en la CCDL, pero también parece negarse a reconocer un derecho constitucional al suicidio. La Corte Suprema de Canadá fundamenta constitucionalmente el derecho a la ayuda médica para morir en el mismo pilar que legitima la limitación del esfuerzo terapéutico o la sedación paliativa que acorta como efecto secundario la vida de los pacientes, es decir, en la libertad de decisión del enfermo.

\section{III.A.2. Riesgos asociados a la legalización}

En el Sumario del caso Carter v Canadá se puede apreciar cómo se analizaron con mucho nivel de detalle los posibles riesgos asociados con la legalización de morir asistido por un médico.

En opinión de la Fiscalía General, hay muchas posibles fuentes de error y hay muchos factores que pueden hacer que un paciente vulnerable sin un deseo racional y claro de morir acabe muerto. En su argumentación describe la fiscalía las siguientes fuentes o factores de error: a) deterioro cognitivo, depresión y otra enfermedad mental, b) coerción, c) influencia indebida, d) manipulación psicológica o emo-

\footnotetext{
${ }^{13}$ Parágrafo 63.
} 
cional, e) el prejuicio sistemático contras las personas mayores o personas con discapacidad, f) y la posibilidad de ambivalencia o diagnóstico erróneo. En esencia, la Fiscalía aduce que, dada la amplitud de esta lista, no hay manera confiable de identificar aquellas personas que son vulnerables de las que no lo son, razón por la cual se hace necesaria una prohibición general de la ayuda para morir.

El juez de primera instancia, y posteriormente la Corte Suprema, ven las cosas de otra forma. En su opinión ${ }^{14}$, «la vulnerabilidad se puede evaluar de forma individual, utilizando los procedimientos que los médicos aplican en su evaluación de consentimiento informado y la capacidad de decisión en el contexto de la toma de decisiones médicas en general. Las preocupaciones acerca de la capacidad de decisión y la vulnerabilidad surgen en toda la toma de decisiones médicas al final de su vida. Lógicamente hablando, no hay ninguna razón para pensar que los heridos, enfermos y discapacitados que tienen la opción de rechazar o solicitar la retirada de tratamiento de soporte vital, o que buscan la sedación paliativa, son menos vulnerables o menos susceptibles a la toma de decisiones sesgadas que los que podrían buscar ayuda más activa en morir. Los riesgos que describen Canadá ya son parte integrante de nuestro sistema médico». Este es, en opinión, un aspecto esencial del caso. Piensa el Tribunal, no sólo que es posible detectar y evaluar la vulnerabilidad de las personas en los procesos de toma de decisiones clínicas con consentimiento informado, sino que de facto esta evaluación individualizada de cada caso ya se está realizando.

Resumiendo, tres son a este respecto las conclusiones más relevantes del alto Tribunal canadiense:

1. Es posible para los médicos, con el debido cuidado y atención a la gravedad de las decisiones involucradas, evaluar adecuadamente la capacidad de decisión de los pacientes.

2. Los riesgos asociados a la muerte con asistencia médica pueden limitarse a través de un sistema cuidadosamente diseñado y supervisado de salvaguardias.

3. Una prohibición general no es necesaria a fin de cumplir sustancialmente los objetivos de protección de la vida y de la población vulnerable. Un miedo teórico o especulativo no puede justificar una prohibición absoluta.

14 Parágrafo 115. 
$\mathrm{Al}$ contrario de lo que se ha visto reflejado en algunas Sentencias del Tribunal Constitucional (TC) español relacionadas con el derecho a la vida ${ }^{15}$, la Corte Suprema de Canadá entiende que no forma parte del juicio de constitucional la tarea de definir de forma pormenorizada los contenidos, requisitos y condiciones que debiera contener ese sistema de garantías. El alto Tribunal canadiense parece comulgar más con la opinión de que los mecanismos exactos que debe contemplar la ley a la hora de regular lo que sería una excepción legítima del deber estatal de protección de la vida, es una función que -so pena de convertir a los Tribunales Constitucionales en una suerte de tercera cámara- debiera corresponder al poder legislativo.

Aborda también la Corte Suprema en su Sentencia el manido tema de la "pendiente resbaladiza», y lo hace de una forma ciertamente somera. El argumento de la Fiscalía canadiense pretende hacer ver que sin la prohibición absoluta de la muerte asistida Canadá descendería la pendiente resbaladiza que le conduciría de forma directa a la eutanasia y el homicidio generalizado e indiscriminado. Sobre este asunto, opina el alto Tribunal que «Ejemplos anecdóticos de casos controvertidos en el extranjero se citaron en apoyo de este argumento, sólo para ser contrarrestada por ejemplos anecdóticos de los sistemas que funcionan bien ${ }^{16}$, de modo que finalmente los magistrados aceptaron los argumentos del juez de primera instancia en el sentido de no presumir a la ligera que el régimen regular necesariamente tenga que funcionar de forma defectuosa.

\section{III.B. El derecho de libertad}

El juez de primera instancia concluyó que la prohibición de la muerte asistida por médico limitó el derecho de la señora Taylor a su libertad y a su seguridad como persona. De alguna forma, la imposición de dolor y de estrés psicológico supone privar a la demandante de control sobre su integridad corporal, privación esta que incide sobre su seguridad personal.

Ya se dejó constancia en primera instancia de que a las personas grave e irremediablemente enfermas se les niega con esta prohibición la oportunidad de tomar una decisión que puede ser muy importante desde el punto de vista de su dignidad e integridad personal, puesto que se trata de una decisión que debe ser consistente con

15 Véase como ejemplo paradigmático de este tipo de excesos la Sentencia 53/1985, de 11 de abril de 1985, del TC sobre la llamada Ley del aborto.

16 Parágrafo 120. 
sus valores y con su experiencia de vida. Pues bien, la Corte Suprema de Canadá se muestra por entero de acuerdo con estas apreciaciones del juez: «La respuesta de un individuo que padece una enfermedad grave e irremediable es una cuestión fundamental para la dignidad y la autonomía. La ley permite a las personas en esta situación solicitar la sedación paliativa, negarse a la nutrición e hidratación artificial, o solicitar el retiro de equipo médico de soporte vital, pero les niega el derecho a solicitar la asistencia de un médico para morir. Esto interfiere con su capacidad para tomar decisiones que afecten a su integridad y a su atención médica y por lo tanto a su libertad corporal ${ }^{17}$. Es en este punto donde algunos autores ${ }^{18}$ han querido ver que en la sentencia Carter se elimina la distinción entre la eutanasia pasiva y activa indirecta, de un lado, y el suicidio asistido y la eutanasia activa directa por otro, haciéndolas coincidir dentro del mismo derecho de autonomía que tiene el paciente para adoptar decisiones médicas en relación con el final de la vida. En mi opinión, más que suprimir las diferencias entre unas prácticas y otras, lo que hace la Corte Suprema de Canadá es subrayar que unos y otros derechos tienen su razón de ser desde el punto de vista del derecho constitucional en un mismo derecho fundamental, que en el caso canadiense sitúan en el art. 7 del CCDL.

Por otro lado, la distinción entre la ayuda médica en el morir (cuidados paliativos que acortan la vida; limitación de esfuerzo terapéutico, retirada de mecanismos de soporte vital,) y la ayuda médica a morir (suicidio asistido por médico, eutanasia médica activa directa), es un asunto no pacífico en la doctrina. Algunos autores no ven la existencia de diferencia ética entre unas prácticas y otras, y hay incluso quienes sostienen que ciertas prácticas adscritas a la llamada eutanasia pasiva (morir lentamente negándose a comer, desconectar respiradores) pueden ser más crueles para el paciente que la práctica de la eutanasia activa ${ }^{19}$. Por el contrario, otros autores de relevancia subrayan la diferencia entre matar o suicidarse y dejarse morir, afirmando que «En los dos primeros casos, la causa de la muerte es el acto de un tercero o del propio paciente, mientras que, en el tercero, la causa de la muerte es la enfermedad subyacente» ${ }^{20}$.

17 Parágrafo 66.

18 Rey MARTínez, Fernando, «La ayuda médica a morir como derecho fundamental (Comentario crítico de la sentencia de la Corte Suprema de Canadá de 6 de febrero de 2015, asunto Carter v. Canadá)» LA LEY 2491/2015, pág. 4.

${ }_{19}$ Véase Dworkin, R. El dominio de la vida. Una discusión acerca del aborto, la eutanasia y la libertad individual, Ariel, Barcelona, 1994, pág., 240.

${ }^{20}$ Rey Mártinez, ob. cit, pág. ${ }^{7}$. 
La conclusión de la Corte Suprema a este respecto resulta clara: los artículos 241.b y 14 del Criminal Code canadiense, en la medida en que prohíben la muerte asistida por un médico de adultos competentes que buscan ayuda para morir como resultado de una condición médica grave e irremediable que causa sufrimiento intolerables de forma perdurable, vulnera los derechos a la libertad y a la seguridad personal recogidos en el art. 7 del CCDL.

\section{III.C. Adecuación a los principios fundamentales de justicia y juicio de proporcionalidad}

El art. 7 del CCDL no especifica cuáles son esos «principios fundamentales de justicia» que nunca se pueden violar cuando se pretenda limitar los derechos a la vida, la libertad o seguridad personales. Ha sido la jurisprudencia de la Corte Suprema de Canadá la que de forma paulatina los ha ido identificando. La propia Sentencia objeto de comentario caracteriza tres de estos principios, definiéndolos de la siguiente forma:

a) El principio de arbitrariedad. Este principio, descrito en el parágrafo 83 de la Sentencia, exige la existencia de una conexión racional entre el objeto de la ley y el límite que impone a los derechos. Una ley sería arbitraria si no fuera capaz de cumplir sus objetivos, es decir, si se cobrara «un precio constitucional en materia de derechos, sin promover el bien público que se dice que es el objeto de la ley».

b) El principio de no sobreinclusión. La pregunta que hay que hacerse a la hora valorar este criterio, comentado en el parágrafo 85 de la Sentencia, es si la ley en cuestión, aunque suprima o limite derechos de manera que en general resulta coherente con el objetivo de la ley, va o no demasiado lejos al negar los derechos de algunos individuos de una manera que no guarda relación con el objeto.

c) El principio de no resultar manifiestamente desproporcionada a su finalidad. En este caso, el foco no está tanto en el impacto de la medida sobre la sociedad o el público en general, sino en su impacto sobre los derechos del demandante. Compara pues el propósito de la ley, tomada en sentido literal, con sus efectos negativos sobre los derechos del demandante.

Admitido como está en el parágrafo 70 de la sentencia que la prohibición general penal al auxilio asistido por médico priva a los demandantes, entre ellos a la señora Taylor, de parte de sus derechos 
constitucionales, queda por dilucidar si esta privación está de acuerdo con los principios de justicia fundamental descritos arriba.

En este punto del debate, se hace imprescindible definir con precisión cuál es el objeto de la prohibición, aspecto éste que de alguna forma ya fue tratado páginas atrás cuando se analizaba los riesgos asociados a la legalización. Como fuere, el juez de primera instancia, partiendo de la jurisprudencia de la Corte Suprema en el caso Rodríguez, llegó a la conclusión de que el objeto de la prohibición era proteger a personas vulnerables que se pudieran ver inducidas a cometer suicidio en un momento de debilidad. Algunos autores alegan que los objetivos de la prohibición pueden ser muchos más ${ }^{21}$.

Recordemos que, en línea con esta argumentación, el gobierno canadiense sostenía que «toda persona es potencialmente vulnerable» (parágrafo 88) y que no es fácil determinar a priori quién es vulnerable y quién no. Pero la Corte Suprema se opone a esta tesis. El Tribunal da la razón al juez de primera instancia y piensa que «No toda persona que desea suicidarse es vulnerable y puede haber personas con discapacidad que tengan un deseo importante, racional y persistente de poner fin a sus vidas» (parágrafo 89). En ese mismo orden de cosas, niega el tribunal que el objeto de la prohibición penal de la ayuda médica a morir fuera la "preservación de la vida» en general, porque tal finalidad sería demasiado amplia e impediría cualquier cambio legal en la materia.

${ }^{21}$ Rey MARTíneZ, en la nota 23 de la obra citada, se refiere entre otros al Informe del Task Force on Life \& the Law del Estado de Nueva York (1994), reseñando que en el Suplemento al Informe, de 1997, se sintetiza los riesgos asociados a una despenalización de la eutanasia y/o del suicidio asistido de la siguiente forma: «1. ${ }^{\circ}$ ) Enfermedad mental no diagnosticada o no correctamente tratada. $\left.2 .^{\circ}\right)$ Síntomas físicos manejados inadecuadamente. $3^{\circ}{ }^{\circ}$ ) Insuficiente atención al sufrimiento y temores de los pacientes en trance de morir. $4 .^{\circ}$ ) Vulnerabilidad de grupos socialmente marginados. 5..$\left.^{\circ}\right)$ Devaluación de la vida de los discapacitados. 6..$^{\circ}$ Sentido de obligación: la legalización del suicidio asistido podría enviar el mensaje de que el suicidio es una respuesta socialmente aceptable a las enfermedades terminales o incurables. Algunos pacientes podrían sentirse presionados a tomar esa opción, particularmente quienes se sienten como una carga para los suyos. $\left.7 .^{\circ}\right)$ Deferencia del paciente hacia las recomendaciones del médico. 8. $^{\circ}$ ) Incentivos económicos a limitar los cuidados paliativos. El suicidio asistido es bastante más barato que los cuidados paliativos y de apoyo en el fin de la vida. 9. $^{\circ}$ ) Arbitrariedad de los límites propuestos. Será difícil, si no imposible, contener la opción del suicidio asistido a los enfermos terminales competentes con sufrimiento incontrolable; previsiblemente se extenderá a enfermos que no son competentes o que no son terminales. $10 .^{\circ}$ ) Imposibilidad de desarrollar un control efectivo. La naturaleza privada e íntima de este tipo de decisiones impedirá cualquier esfuerzo por controlar los eventuales errores y abusos». Como ha quedado dicho, en esa misma línea se posicionan los argumentos del Fiscal General de Canadá en la Sentencia objeto de comentario. 
Despejado este asunto, central para poder analizar si el Código Penal canadiense vulnera o no los llamados «principios fundamentales de justicia», entra el Tribunal a realizar ese análisis.

A este respecto, la primera afirmación que realiza el Tribunal (parágrafo 84) es que «El objeto de la prohibición de morir asistido por un médico es proteger a las personas vulnerables de poner fin a su vida en momentos de debilidad. La prohibición total de la asistencia suicidio claramente ayuda a lograr este objetivo. Por lo tanto, los derechos de los individuos no se limitan arbitrariamente», ya que existe una conexión racional entre la limitación de la ley y el objeto que ésta se propone.

Sin embargo, cuando llega la hora de analizar el segundo principio descrito -análisis éste que se convierte en el corazón del caso desde el punto de vista jurídico- la conclusión es negativa. La pregunta en este caso es si existen medios menos perjudiciales que la prohibición absoluta para alcanzar el objetivo legislativo. La responsabilidad de demostrar que no existen esos otros posibles medios recae, en opinión del Tribunal, en el Gobierno.

El juez de primera instancia -opinión ésta compartida por la Corte Suprema (parágrafo 104) - opina que una prohibición absoluta habría sido necesaria si a) la evidencia mostrara que los médicos fueran incapaces de evaluar de forma fiable la competencia, la voluntariedad, y no ambivalencia en los pacientes; b) si los médicos no fueran capaces de entender o aplicar el requisito de consentimiento informado para el tratamiento médico; o c) si la evidencia de jurisdicciones permisivas mostrara el abuso de los pacientes, el descuido, la insensibilidad, o una pendiente resbaladiza, lo que lleva a la terminación informal de la vida. Pues bien, ninguna de esas circunstancias han quedado acreditadas durante el proceso, en opinión del alto Tribunal.

Ya en primera instancia, el juez encontró que era factible que los médicos debidamente cualificados y con experiencia pudieran evaluar de forma fiable la competencia del paciente y la voluntariedad, detectando posibles elementos de coacción, influencia indebida o de ambivalencia que pudieran darse en algunos casos. Para llegar a esa conclusión, se basó sobre todo en la evidencia empírica que suponía la aplicación en decenas de miles de casos de la norma de consentimiento informado en otras tomas de decisiones médicas en Canadá, incluyendo las relativas a las que hacen referencia al final de la vida.

Piensa igualmente el Tribunal (parágrafo 105) que una regulación permisiva con las salvaguardias adecuadamente diseñadas y admi- 
nistradas, era capaz de proteger a las personas vulnerables contra el abuso y el error. El convencimiento de los magistrados es que, si bien hay riesgos, un sistema bien diseñado y cuidadosamente administrado es capaz de hacer frente a ellos: «...los riesgos inherentes derivados de permitir la muerte asistida por un médico pueden ser identificados y muy sustancialmente minimizados a través de un sistema cuidadosamente diseñado capaz de imponen límites estrictos que se monitorean y hacen cumplir escrupulosamente».

\section{III.D. El fallo}

En conclusión, y por las razones descritas, la sentencia falla que la prohibición absoluta de la ayuda al suicidio no es la medida limitativa del derecho menos gravosa y que resulta por consiguiente desproporcionada, declarando nulos a renglón seguido los artículo 241 (b) y el artículo 14 del Código Penal, en la medida que prohíben la muerte con asistencia médica para una persona adulta competente que (a) da claramente su consentimiento a la terminación de la vida; y (2) tiene una condición médica grave e irremediable que causa sufrimiento duradero y que es intolerable para el individuo en las circunstancias de su condición. Se declaran nulos por tanto dichos artículos, y se invita al Parlamento y a las legislaturas provinciales para responder, si así lo deciden, mediante la promulgación de una legislación coherente con los parámetros constitucionales establecidos en esta sentencia.

Como es costumbre en la práctica judicial relativa a la constitucionalidad de las leyes, cuando la Corte Suprema de Canadá examina el contraste de la norma impugnada con ciertos elementos, en cuanto concluye que viola algunos de ellos, ya no pasa a examinar el resto. En la Sentencia que está siendo objeto de comentario aquí, al constatar que la prohibición penal de la ayuda a morir lesiona el derecho a la vida, la libertad y seguridad personales del art. 7 del CCDL, ya no entra al estudio de si viola igualmente o no el derecho de igualdad del artículo 15.

Resulta también de interés destacar que, en opinión del Tribunal, el nuevo derecho que se reconoce tiene su encaje constitucional en el artículo 7 de la CCDL ${ }^{22}$, y que corresponde al poder legislativo fijar los contornos, contenido y límites de este derecho, no resultando

22 Conviene reseñar llegado a este punto que, en lo que sería una transposición razonable de los preceptos constitucionales recogidas en la Carta Canadiense respecto de la Constitución española de 1978 (CE), lo que en la CCDL llaman derecho a la «seguridad personal» coincide más con el haz de derechos integrados en el art. $15 \mathrm{CE}$ 
necesario una modificación del texto constitucional a través de una previa reforma. De hecho, aún a pesar de que la mayoría de la Corte de Apelación sugirió al Tribunal posibilidad de emitir una exención constitucional independiente, en lugar de una declaración de nulidad en el caso de que optará por reconsiderar la jurisprudencia sentada en el caso Rodríguez, el Tribunal no le parecía esta vía un remedio apropiado: «Hemos encontrado que la prohibición viola los derechos de los reclamantes contenidos en el artículo 7 CCDL. El parlamento debe tener la oportunidad de elaborar un remedio apropiado» (parágrafo 125).

Pudiera parecer un tanto extraño que conductas penalizadas como delitos pasen sin solución de continuidad a constituir parte del contenido esencial de un derecho fundamental, pero como es sabido existen precedentes en otras materias -el caso de la homosexualidad es uno de ellos-, en la que la aprobación de leyes asociadas al contenido esencial de ciertos derechos fundamentales tampoco ha requeridos de modificaciones en el texto constitucional.

\section{PROPUESTA DE LEY DEL GOBIERNO CANADIENSE}

El remedio apropiado del que habla la sentencia de la Corte Suprema en su parágrafo 125 adoptó finalmente forma de una Propuesta de Ley que Justin Trudeau, primer ministro de Canadá, presentó el 14 de abril del 2016 con el fin de legalizar en Canadá la asistencia médica para morir en los casos de enfermos con condiciones médicas "graves e irreversibles» $\mathrm{y}$ «que se acerquen al final de su vida».

Como ha quedado dicho, la Corte Suprema de Canadá en la Sentencia del caso Carter dio un plazo de un año al Gobierno para crear una nueva legislación, pero el ejecutivo de Canadá, liderado en aquellos meses por el conservador Stephen Harper, nunca dio pasos en esta dirección.

El cambio de Gobierno en el país, la propia sentencia de la Corte Suprema, la postura no beligerante de las Asociaciones de Médicos canadienses, y el respaldo de los ciudadanos a la medida - un $77 \%$ de los canadienses respaldaría por ejemplo el suicidio asistido, según Forum Research-, fueron factores determinantes que propiciaron la toma de posición del Ejecutivo canadiense. Con todo y eso, el primer

referido a la integridad «física y moral», que con el derecho a la libertad y a la seguridad personal explicitada en el art. $17 \mathrm{CE}$. 
ministro ${ }^{23}$ ofreció expresamente a los miembros de su partido la posibilidad de que voten en contra de la legislación si ésta entra en conflicto con su fe, lo que muestra la naturaleza delicada y compleja de los asuntos puestos en cuestión. Así las cosas, el Gobierno solicitó y la Corte Suprema concedió una prórroga para aprobar esta ley antes del 6 de junio de 2016. Veamos ahora los contenidos básicos de esa Propuesta de Ley.

\section{IV.A. Modificación del Código penal en orden a crear excepciones para el delito de homicidio consentido, la ayuda en el suicidio, y la administración de sustancias nocivas}

Según consta en el Preámbulo del Proyecto de $\mathrm{Ley}^{24}$, el Gobierno canadiense parte de la convicción de que: «...permitiendo el acceso a la asistencia médica al morir a adultos competentes cuyas muertes son razonablemente previsibles se logra el equilibrio más adecuado entre la autonomía de las personas que buscan ayuda médica para morir, por un lado, y los intereses de las personas vulnerables que necesitan protección y los de la sociedad, por el otro».

De prosperar el Proyecto de Ley presentado por el gobierno canadiense, la inducción o la ayuda en el acto suicida seguirán estando penadas en el Código Penal canadiense con penas que pueden llegar a los 14 años de cárcel. De hecho, la sección 241.1 quedaría redactado con un texto del siguiente tenor: "Todo el mundo es culpable de un delito grave y susceptible de prisión por un término no mayor de 14 años, tanto si sobrevive el suicida como si no, si (a) aconseja a una persona morir por suicidio o instiga a una persona para morir por suicidio; o (b) ayuda a una persona a morir por suicidio». Ahora bien, según lo estipulado en los incisos 1, 2, 3, 4 y 5 del citado artículo, ni el médico, ni la enfermera practicante, ni el farmacéutico, ni ninguna otra persona que ayude a estos a prestar a una persona asistencia médica en el morir cometerán delito alguno, si lo hacen de conformidad con lo estipulado en la sección 241.2.

${ }^{23}$ La postura personal de Justin Trudeau respecto a la muerte quedó marcada por el fallecimiento de su padre en el año 2000 después de padecer Parkinson y cáncer de próstata.

${ }^{24}$ Proyecto de ley C-14 «Una ley para modificar el Código Penal y de efectuar modificaciones relacionadas a otras leyes (asistencia médica en la muerte). Primera lectura 14 de abril de 2016. Ministerio de Justicia 90795. 


\section{IV.B. Definiciones y sistema de garantías}

A efectos del debate en curso, resulta vital explicar qué es lo que el Proyecto de Ley entiende por «asistencia médica para morir». En el inciso 7 del art. 241.1 se puede leer qué entiende el Ejecutivo canadiense por tal concepto:

«(a) la administración por un médico o enfermera practicante de una sustancia a una persona, a petición de éstos, que lleva a su muerte; o

(b) la prescripción o la prestación de un médico o una enfermera de una sustancia a una persona, a petición de éstos, para que puedan auto-administrarse la sustancia y al hacerlo, provocar su propia muerte».

Es decir, los contenidos de las excepciones a las que hace referencia el Proyecto de Ley se refieren tanto a lo que se conoce como «suicidio asistido por médico», como a la «eutanasia activa directa».

Otro aspecto a destacar es que la administración o el suministro de la sustancia legal puede ser realizada tanto por un médico como por una «enfermera practicante», entendiendo por tal «...una enfermera registrada que, bajo las leyes de una provincia, tiene derecho a ejercer como profesional de enfermería -o con una denominación equivalente- a hacer diagnósticos de forma autónoma, ordenar e interpretar las pruebas de diagnóstico, prescribir sustancias y tratar a los pacientes».

Ahora veamos cómo define el Proyecto de Ley a los titulares de estos derechos. Según lo estipulado en el art. 241.2 inciso primero del Proyecto de Ley, una persona puede recibir asistencia médica para morir si cumple de forma simultánea con los criterios que se enumeran a continuación:

a) Si son beneficiarios de los servicios de salud financiados por el gobierno de Canadá (es decir, si son ciudadanos canadienses).

b) si tienen al menos 18 años de edad y son capaces de tomar decisiones con respecto a su salud.

c) si tienen una condición médica grave e irremediable.

d) si han realizado una solicitud voluntaria de asistencia médica para morir que no se dio como resultado de la presión externa; y.

e) si dan su consentimiento informado para recibir asistencia médica en morir. 
En el inciso segundo del artículo 241.2 se define el estado de «dolencia dolorosa e irremediable» como el que padecen aquellas personas que:

a) Tienen una enfermedad o discapacidad grave e incurable;

b) se encuentran en un estado de deterioro avanzado e irreversible de su capacidad;

c) la enfermedad, discapacidad o estado de deterioro les hace soportar un sufrimiento físico o psicológico que resulta intolerable para ellos y que no pueden aliviar en condiciones que consideren aceptables;

d) la muerte natural se ha convertido en algo razonablemente previsible teniendo en cuenta todas las circunstancias médicas, sin que necesariamente se requiera un pronóstico exacto del tiempo de vida que les queda.

En mi opinión, y a la vista de los citados requisitos, resultaría muy difícil que personas que simplemente desearan morir -incluso si probasen padecer graves dolencias físicas o psicológicas ${ }^{25}$ - pudieran arrogarse la titularidad de los derechos contemplados en este Proyecto de Ley. En la mayoría de estos casos, ni la enfermedad resultaría «incurable», ni el deterioro aparecería como necesariamente «irreversible», ni por supuesto la muerte natural surgiría como un fenómeno «razonablemente previsible».

\section{IV.C. Seguimiento y control de los procesos}

En el inciso tercero del artículo 241.2 se estipulan una serie de salvaguardias y garantías que resultan de imprescindible comentario.

El primero de ellos hace referencia a que, antes de que un médico o una enfermera practicante proporcione a una persona asistencia médica para morir, el médico o la enfermera debe ser de la opinión de que la persona cumple con todos los criterios establecidos en el inciso primero de este mismo artículo.

${ }^{25}$ Imaginémonos, por ejemplo, el caso típico de un desengaño amoroso que produjera en alguno de sus protagonistas un dolor o incomodidad vital y psicológica ciertamente importante en el marco de un proceso depresivo grave. 
La segunda de estas salvaguardias hace referencia al documento que firman los solicitantes, en el sentido de que estos médicos o enfermeros deben asegurarse de que la solicitud de la persona:

a) se realice por escrito y esté firmado por la persona solicitante o por otra persona ${ }^{26}$,

b) y que dicha solicitud está firmada y fechada después de que la persona haya sido informada por un médico o enfermera practicante de que la muerte natural de la persona se ha convertido en razonablemente previsible, teniendo en cuenta la totalidad de sus circunstancias médicas.

La tercera salvaguardia hace referencia a una exigencia de convencimiento por parte de estos médicos o enfermeras de que la solicitud ha sido firmada ante dos testigos independientes cuya firma consta en la solicitud.

Puede ocupar el rol de "testigo independiente» cualquier persona que tenga al menos 18 años de edad y que entienda la naturaleza de la solicitud de asistencia médica para morir, con las siguientes excepciones $^{27}$ :

a) si puede ser beneficiario de acuerdo con la voluntad de la persona que hace la solicitud, o un receptor, de cualquier otro modo, de un beneficio financiero o material resultante de la muerte de esa persona;

b) si es un propietario u operador de cualquier centro de atención médica en la que la persona que haya sido tratado la persona que realiza la solicitud;

c) si está directamente involucrado en la prestación de servicios de salud a la persona que hace la solicitud; o

d) si proporciona directamente el cuidado personal de la persona que realiza la solicitud.

La cuarta salvaguardia exige a los médicos y enfermeras que vayan a prestar asistencia para morir que se aseguren de que la persona ha sido informada de que puede, en cualquier momento y de cualquier manera, retirar su solicitud.

${ }^{26}$ En el inciso cuarto del artículo 241.2 se estipula que «Si la persona que solicita la asistencia médica en la muerte no puede firmar y fechar la solicitud, otra persona -que tiene por lo menos 18 años de edad y que comprende la naturaleza de la solicitud de asistencia médica para morir- puede hacerlo en nombre y en presencia de la persona solicitante».

27 Inciso 5 del artículo 241.2 
La quinta salvaguardia exige que otro médico o enfermera practicante emita una opinión escrita en el sentido de que la persona solicitante cumple con todos los requisitos establecidos en el inciso primero 241.2.

La sexta salvaguardia se refiere a que el médico o enfermera practicante al que se hace referencia en el apartado anterior debe ser «independiente» del primero; se entenderán que son independientes ${ }^{28}$ si:

a) no se encuentran en una relación de negocios con el otro médico, o es responsable de supervisar su trabajo;

b) no son beneficiarios, de acuerdo con la voluntad de la persona que hace la solicitud, o receptores de cualquier otro modo, de un beneficio financiero o material resultante de la muerte de esa persona, que no sea una compensación estándar para sus servicios relacionados con la solicitud; o

c) no están conectados con el otro médico o enfermera prácticamente, o con la persona que realiza la solicitud, en cualquier otra forma que afecte su objetividad.

La séptima garantía hace referencia a deben transcurrir al menos 15 días entre que se firma la solicitud y la fecha en que se proporciona la asistencia médica ${ }^{29}$.

Por último, se estipula que, «inmediatamente antes de proporcionar la asistencia médica en la muerte, se dará a la persona la oportunidad de retirar su solicitud, asegurándose de que la persona da su consentimiento expreso para recibir asistencia médica en morir».

\section{IV.D. Régimen sancionador}

El incumplimiento de alguna de estas garantías resulta tipificado en el Código Penal canadiense, de modo que ${ }^{30}$ «Un médico o enfermera practicante de medicina que, en la prestación de la asistencia médica en la muerte, a sabiendas, no cumple con todos los requisitos establecidos en los párrafos 241.2 (3) (b) a (h) y el inciso 241.2 (8) es

28 Inciso 6 del artículo 241.2

${ }^{29}$ En esta garantía se prevé también la posibilidad de que el médico o la enfermera practicante (tanto el titular como el independiente) sean ambos de la opinión de que «la muerte de la persona, o la pérdida de su capacidad para dar su consentimiento informado" sea inminente, en cuyo caso puede estipularse un período más corto de tiempo que debe ser consensuado entre ambos médicos o enfermeras titulares.

30241.3 de la Propuesta de Ley. 
culpable de un delito y está sujeta a) en sentencia condenatoria, a una pena de prisión de no más de cinco años; o b) en sentencia sumaria, a una pena de prisión de no más de 18 meses». Igualmente, la falsificación o destrucción de documentos asociados a estos procesos de ayuda en el morir se consideran delitos cuya pena puede oscilar de los 18 meses en sentencia sumaria, a los 5 años en sentencia condenatoria.

Igualmente, este Proyecto de Ley hace referencia también a algunas modificaciones correspondientes en otras Leyes distintas al Código Penal; pretende garantizar, por ejemplo, que el recurso a la asistencia médica en la muerte no da lugar a la pérdida de una pensión en virtud de la Ley o los beneficios de pensión a que la Ley obliga a los miembros y veteranos restablecimiento y Compensación canadiense. Se modifica también la Ley de Corrección y libertad condicional para garantizar que no es necesario realizar una investigación en virtud del artículo 19 de la citada Ley en el caso de un preso que recibe la asistencia médica para morir.

\section{CONCLUSIONES}

1. En la Sentencia Carter v. Canadá se parte de un problema social (definido como la "cruel dicotomía» a la que se condena a ciertas personas grave e irremediablemente enfermas, consistente en quitarse la vida la vida antes de tiempo, a menudo a través de medios violentos y peligrosos, o prolongar el sufrimiento hasta que mueran por causas naturales), para analizar a continuación el problema estrictamente jurídico: esta prohibición general ¿viola la Carta canadiense de Derechos y Libertades, especialmente el artículo 7 de la misma referido al derecho a la vida, a la libertad y a la seguridad de la persona?

2. La jurisprudencia seguida hasta la fecha por la propia Corte Suprema de Canadá, asentada en el llamado caso Rodríguez y que resultaba negativa respecto a la posibilidad de plantear excepciones a la prohibición general de ayuda médica para morir, se basaba en las siguientes premisas: a) la aceptación generalizada de una distinción moral o ética entre eutanasia activa y eutanasia pasiva, b) la falta de una «medida a mitad de camino» que podría proteger a los vulnerables, y c) el «consenso sustancial» en los países occidentales de que es necesaria una prohibición general para la protección contra la pendiente resbaladiza. Pues bien, en opinión de la Corte Suprema, se presentaron en primera instancia pruebas que, de ser aceptadas, eran capaces de minar cada una de estas premisas. 
3. El tribunal, después de fijar como objetivo esencial de la prohibición general de la ayuda médica para morir el de proteger a personas vulnerables que se pudieran ver inducidas a cometer suicidio en un momento de debilidad, el alto Tribunal canadiense llega a las siguientes conclusiones: a) Es posible para los médicos evaluar adecuadamente la capacidad de decisión de los pacientes; b) Los riesgos asociados con la muerte con asistencia médica pueden limitarse a través de un sistema cuidadosamente diseñado y supervisado de salvaguardias; y c) Una prohibición general no es necesaria a fin de cumplir sustancialmente los objetivos de protección de la vida y de la población vulnerable.

4. La Corte Suprema de Canadá concluye en su Sentencia que, aún a pesar de existir una conexión racional entre la limitación de la ley y el objeto que ésta se propone, los artículos 241.b) y 14 del Criminal Code canadiense, en la medida en que prohíben la muerte asistida por un médico de adultos competentes que buscan ayuda para morir como resultado de una condición médica grave e irremediable que causa sufrimiento intolerables de forma perdurable, vulnera los derechos a la libertad y a la seguridad personal recogidos en el artículo 7 del CCDL. Existen, en opinión del alto Tribunal, formas menos perjudiciales que la prohibición absoluta para alcanzar ese objetivo legislativo.

5. La Corte Suprema de Canadá fundamenta constitucionalmente el derecho a la ayuda médica para morir en el mismo pilar que legitima la limitación del esfuerzo terapéutico o la sedación paliativa que acorta como efecto secundario la vida de los pacientes, es decir, en el derecho a la libertad recogido en el artículo 7 de la CCDL, artículo éste que, con matices, tendría su correlato en el derecho fundamental a la integridad física y moral recogido en el art. 15 de la Constitución española de 1978.

6. Atendiendo a lo solicitado en el fallo del caso Carter, el gobierno de Canadá presentó el 14 de abril de 2016 un Proyecto de Ley con el fin de legalizar en Canadá la asistencia médica para morir en los casos de enfermos con condiciones médicas «graves e irreversibles» y «que se acerquen al final de su vida».

7. La nueva legislación sigue manteniendo en la ilegalidad la inducción y la ayuda en el morir con penas de hasta 14 años de cárcel, pero fija unas excepciones dirigidas a una población concreta que ejercite su derecho a la excepción a través de procedimientos específicos, que son los reseñados en el nuevo art. 241.2 del Código Penal. 
8. Respecto a la pregunta de qué prácticas son las excepcionadas, el Proyecto de Ley menciona expresamente tanto la conocida como eutanasia activa directa como el suicidio asistido por médico, es decir, tanto la administración por parte de un médico de una sustancia a una persona, a petición de ésta, que la lleva a su muerte, como la prescripción de una sustancias para que éstos puedan auto-administrarse la misma.

9. Los beneficiarios de este nuevo derecho quedan tipificados de la siguiente forma: a) se circunscribe a los beneficiarios del sistema de salud canadiense, b) deben tener al menos 18 años de edad y ser capaces de tomar decisiones respecto a su salud, c) deben padecer una condición médica grave e irremediable, y d) deben haber realizado una solicitud voluntaria, previo consentimiento informado, de asistencia médica para morir.

10. Además de definir esa condición "grave e irremediable», la Propuesta de Ley estipula una serie de garantías y salvedades que podrían sintetizase de la siguiente forma: a) dos médicos independientes uno de otro, deben certificar que el paciente cumple todas las condiciones, b) la solicitud debe ser escrita, y debe ser firmada después de la persona haya sido debidamente informada de su diagnóstico y de las consecuencias de su decisión, c) la firma de la solicitud se hace ante dos testigos independientes, d) el solicitante puede retirar su solicitud en cualquier momento y de cualquier forma, y f) deben transcurrir al menos 15 días entre la solicitud y la recepción de la asistencia médica para morir. 
